undue emphasis on a few classic, easily recognised infections, like smallpox and the plague, in historical records and Mediaeval 'flu has been overlooked.

The book is produced to a high standard and my only complaint is a minor one: the text does not always stick to the subheading under which it is placed, and, for example, a discussion on the size of the population units between which variation becomes important for any polymorphism ends up under 'neoplasms'.

For those actively involved in the study of disease associations the Tables and bibliography alone justify the $£ 25 \cdot 00$. The rest of us can reasonably expect all but the smallest libraries we use to have a copy of this and 'The Distribution of the Human Blood Groups and Other Polymorphisms'. Ideas may change but the carefully compiled Tables in both these volumes will remain an invaluable source of information for a long time to come.

Marcus E. Pembrey

\section{Inherited Disorders of the Skeleton}

By Peter Beighton. (Pp. xvii +267 ; Figures +

Tables. £16.00.) Edinburgh, London, and

New York: Churchill Livingstone. 1978.

There is a great need for monographs on the genetics of the various system specialities, so that both this book and the series of which it is the first example are to be welcomed. The book provides a thumbnail sketch of the clinical features and the genetics of over 120 different disorders affecting the skeleton. The 'inherited disorders' of the title is taken fairly literally, in that common but nonMendelian conditions, such as congenital dislocation of the hip, talipes equinovarus, and idiopathic scoliosis are not discussed, though several rarer malformations and 'anomalads' with no known genetic basis are included. Roughly half of the conditions covered are illustrated by useful black and white photographs, which add greatly to the book's value. The vast majority of them appear to be of the author's own patients, attesting to his wide experience in this field.

The grouping of various types of disorder into chapters seems at times rather arbitrary. I suspect that this was done to make the chapters of manageable length, but it also causes difficulties in finding one's way around, especially in the first three chapters entitled 'Skeletal dysplasias without significant spinal involvement' (this, curiously, includes achondroplasia and chondrodysplasia punctata), 'Skeletal dysplasias with significant spinal involvement', and 'Miscellaneous skeletal dysplasias' (which includes several syndromes not usually thought of as skeletal dysplasias). Similarly, the three chapters entitled 'Osteoscleroses', 'Crani䒜 tubular dysplasias', and 'Craniotubular hyperostoses' separate some entities which, superficially, seem t䲩 have quite a lot in common.

Partly as a result of its organisation, the book not as helpful as it might have been where the diagnosis is not known. This could have been remedied by including some flow diagrams fof differential diagnosis in such clinical problems $2(3$ short limbed dwarfism of pre- and postnatal onse $\vec{\emptyset}$ increased bone density, the child who appears to have a storage disorder, and so on, and by a mores consistent attempt to lay down definitive criteria fof: each condition. Another useful innovation would bo to show growth curves for some of the dwarfing conditions on a centile chart, indicating wheres possible the expected adult height.

Although the blurb on the jacket says that the boo is 'based on the case histories of more than 1000 " patients . . . examined by the author in genetics clinics in Southern Africa', and Professor Beighton's experience and authority are evident on every page the book is in fact based, as it must be, at least equally on a review of the relevant literature $\overrightarrow{0}$ References up to 1977 are quoted and their contento and bearing, particularly on the questions of genetics, expertly summarised. One occasionally wishes the author would allow his personal pre ferences and practices more play when discussing contentious or difficult issues. For example, how does he actually counsel the sporadic case of pseudoachondroplasia? How thoroughly would he्ध want to examine the apparently normal parents of a child with Freeman-Sheldon or Larsen syndrome?

The references are unfortunately grouped under different topics at the end of each chapter. It woul $\bar{\Phi}$ save a lot of page turning if the references for each topic were given immediately after the relevan section of text.

These are relatively minor quibbles compare with the positive value of the book. Professof Beighton has done clinical geneticists, paediatricians? and orthopaedic surgeons a service in presenting great deal of information in reasonably short and: readable form. It is hoped that he will keep the boof up to date with frequent new editions. The publishers are to be congratulated on making the book portable without lowering standards of production.

N. R. DENNF

\section{The Study of Man. An Introduction to Human Biology}

2nd Edition. By E. J. Clegg. (Pp. v + 330;

Figures + Tables. $£ 6 \cdot 50$ hardback, $£ 3 \cdot 25$ paperback.) London, Sydney, Auckland, Toronto: Hodder and Stoughton. 1978. 
The first edition of Professor Clegg's little book published in 1968 soon proved a firm favourite as an introduction to modern human biology, and this second edition promises to be equally successful. Revised and brought up to date (over $70 \%$ of the bibliography has been published since the first edition), it follows the theme of its predecessor. Its first aim is to introduce important features of the population biology of man to those whose work requires a knowledge of structure and function of the human body. Its second is to illustrate human diversity for the general reader, to help him appreciate that there is more to human differences than meets the eye, and that such differences are of biological importance.

After a brief historical introduction sketching the trends in development of biological studies of man, the second chapter (accounting for almost half the book) sets out the genetic basis of human variation. Its first section on genes in individuals covers Mendel's laws, formation of germ cells, molecular genetics, modes of inheritance, the genetics of sex, linkage and crossing-over, genetic interactions, multifactorial inheritance, cytogenetics, and chromosome abnormalities. This is a remarkably clear introduction; for example, the author skates with precision on the dangerous ice of partial sex linkage, sex limited inheritance, and genetic interaction. The second section on genes in populations examines the genetical consequences of random mating, deviations from it, changes in gene frequencies in populations and the factors responsible for them, and the maintenance of genetic variability in populations, all briefly and clearly. So much for the principles; the next section examines a variety of characters one by one, summarising what is known of their genetics, from blood groups to IQ, and ends with some clear criticisms of incorrect views on race biology.

Chapter 3 concerns growth and aging. Growth in different tissues, measurement and control of growth, the effects of environmental factors, senescence and its causation, are all dealt with rapidly and efficiently, with most attention to adolescence. In the following chapter on the evolution of man the emphasis is mainly on the fossil evidence, and there is relatively little on present-day primates. There is a clear presentation of the features of the main hominid fossil groups, avoiding so much of the controversy attaching to the position of individual specimens, which comes down quite clearly in favour of a monophyletic origin of all varieties of Homo sapiens.

Chapter 5 deals with the intimate relationships that exist between man and the various environments in which he lives, human ecology and, particularly, nutritional, climatic, altitudinal, and biotic ecology. This leads naturally to the question 'how successful an animal is man?'. This chapter is largely concerned with demography, population numbers and density, fertility and mortality, and population changes with time.

The final chapter on the future of man draws attention to the problems of expanding populations and limited resources, and the damage that is being done to the environment at all levels. Prospects for the future appear bleak, but Professor Clegg makes no apology for his pessimistic forecasts, for they are clearly argued and are important in that they dispel the complacency of the many who assume that with improved technology and careful economic management the standard of life of all people can be raised continually. It calls for a conscious effort to limit our economic and industrial activities, to take the difficult and, in many respects, unpleasant steps which are necessary to ensure the survival of our species.

There are a few small points at which criticism can be levelled; for example, an inadequate key to Fig. 6.4, an apparent loss of centromeres in meiosis in Fig. 2.1, the absence of an explicit statement on page 73 that it is only when a single locus is considered that Hardy-Weinberg frequencies become established in the first generation, and perhaps a tooready acceptance of the isogenes in tribal Australia without considering the effect of sampling in the material from which they were drawn. One may question the statement that it was the success of the eugenics movement before the Second World War that held back development of human genetics, for it was rather its misapplication by the genetically uninformed which was responsible. But these criticisms are all minor, and though there is little medical genetic material in the book, it provides an excellent introduction to genetic principles in the second chapter. The book as a whole provides an excellent background on the biology of man against which the efforts and endeavours of medical geneticists can be viewed.

\section{F. ROBERTS}

\section{Textbook of Human Genetics}

2nd ed. By Max Levitan and Ashley Montagu.

Revised by Max Levitan (Pp. $x+1012$;

Figures + Tables. £15.50.)

New York and Oxford: Oxford University Press. 1977.

Undergraduate textbooks of human genetics tend to fall roughly into two main categories. Firstly, those with a predominantly medical orientation, designed mainly for medical students, where the emphasis is on the more practical applications of knowledge. 